\title{
Reliability and Validity of the INFOOT Three-dimensional Foot Digitizer for Patients with Rheumatoid Arthritis
}

\author{
Sophie De Mits, PT, BPod* \\ Pascal Coorevits, PhD, PT, BICT† \\ Dirk De Clercq, PhD, PE‡ \\ Dirk Elewaut, PhD, MD§ \\ James Woodburn, PhD, MPhil, BScף \\ Philip Roosen, PhD, PT, BPod*
}

\begin{abstract}
Background: Abnormal foot posture and deformities are identified as important features in rheumatoid arthritis. There is still no consensus regarding the optimum technique(s) for quantifying these features; hence, a foot digitizer might be used as an objective measurement tool. We sought to assess the validity and reliability of the INFOOT digitizer.

Methods: To investigate the validity of the INFOOT digitizer compared with clinical measurements, we calculated Pearson correlation coefficients. To investigate the reliability of the INFOOT digitizer, we calculated intraclass correlation coefficients, SEMs, smallest detectable differences, and smallest detectable difference percentages.

Results: Most of the 38 parameters showed good intraclass correlation coefficients, with values greater than 0.9 for 30 parameters and greater than 0.8 for seven parameters. The left heel bone angle expressed a moderate correlation, with a value of 0.609 . The SEM values varied between 0.31 and $3.51 \mathrm{~mm}$ for the length and width measures, between 0.74 and $5.58 \mathrm{~mm}$ for the height data, between 0.75 and $5.9 \mathrm{~mm}$ for the circumferences, and between $0.78^{\circ}$ and $2.98^{\circ}$ for the angles. The smallest detectable difference values ranged from 0.86 to $16.36 \mathrm{~mm}$ for length, width, height, and circumference measures and from $2.17^{\circ}$ to $8.26^{\circ}$ for the angle measures. For the validity of the INFOOT three-dimensional foot digitizer, Pearson correlation coefficients varied between 0.750 and 0.997 .
\end{abstract}

Conclusions: In this rheumatoid arthritis population, good validity was demonstrated compared with clinical measurements, and most of the obtained parameters proved to be reliable. (J Am Podiatr Med Assoc 101(3): 198-207, 2011)

Rheumatoid arthritis is a chronic, inflammatory, systemic disease still with an unknown cause. The prevalence in the Western population is estimated

\footnotetext{
*Department of Rehabilitation Sciences and Physiotherapy, Ghent University \& Artevelde University.

$\dagger$ Department of Public Health and RAMIT vzw, Ghent University, Ghent, Belgium.

$\ddagger$ Department of Movement and Sport Sciences, Ghent University, Ghent, Belgium.

§Department of Rheumatology, Ghent University Hospital, Ghent, Belgium.

ףSchool of Health and Social Care and HealthQWest, Glasgow Caledonian University, Glasgow, Scotland.

Corresponding author: Sophie De Mits, PT, BPod, Department of Rehabilitation Sciences and Physiotherapy, Ghent University \& Artevelde University College, De Pintelaan 185 Gent, 9000, Belgium. (E-mail: Sophie.DeMits@UGent.be)
}

to be as high as $0.5 \%$ to $1.0 \%{ }^{1}$ In the rheumatoid arthritis population, foot problems have been reported for $80 \%$ to $94 \%$ of patients. ${ }^{2,3}$ Foot deformities, such as hallux valgus, lesser toe deformations, and pes planovalgus, are some of the most remarkable features in rheumatoid arthritis. ${ }^{3}$ Objectively reporting these deformities and their changes over time is a major challenge.

Despite a variety of clinical methods, there is no consensus regarding the optimum technique(s) for quantifying foot posture. ${ }^{4}$ Furthermore, each measurement predominantly contributes to assessment of the foot in one plane. Consequently, several methods are needed to obtain a full picture of the foot, which is a time-consuming task. ${ }^{4}$ 
Two indices have been developed to evaluate the foot: the Structural Index ${ }^{5}$ and the Foot Posture Index. ${ }^{6}$ The Structural Index summates hallux valgus, fifth metatarsophalangeal joint exostosis, claw/hammer toe, and metatarsophalangeal joint subluxations for the forefoot (score range, 0-12) and calcaneus valgus/varus, ankle range of motion, and pes planus/cavus deformities for the rearfoot (score range, $0-7) .{ }^{5}$ The Foot Posture Index is a sixitem measure for quantifying variation in the position of the foot easily and quickly in a clinical setting. The Foot Posture Index scores palpation of the talar head, curvature of the malleoli, inversion/ eversion of the calcaneus, bulging of the talonavicular joint region, the medial longitudinal arch, and abduction/adduction of the forefoot on a 5-point Likert-type scale $(-2$ to +2$)$. Lower scores represent a more supinated foot position and higher scores a more pronated position. ${ }^{6}$ However, the Foot Posture Index has no items for the forefoot, the most involved site for abnormality in rheumatoid arthritis.

Clinical judgment is also considered to be the gold standard for assessing progression of deformity, although there is a lack of agreement among clinicians. Hence, this points out the need for an objective method for measuring this progression of deformity. ${ }^{7}$

Besides clinical techniques, radiographic investigation of the foot is commonly used for assessment, diagnostic, and comparative purposes. ${ }^{8}$ Although radiography allows exact measurements of the bony structures of the foot, it requires more time and resources than do other methods ${ }^{8}$ and exposes the patient to ionizing radiation.

An easy-to-use, quick, relatively inexpensive, and noninvasive method for acquiring a three-dimensional (3-D) image of the foot is a foot digitizer. So far, these are scarcely used for clinical and research purposes. Some researchers have used a digitizer to scan plaster casts, ${ }^{9-12}$ and others have scanned feet ${ }^{13-16}$ or feet and shoes to check for the proper fit. ${ }^{17-19}$ Digitizers could be used to picture and measure feet in different pathologic abnormalities where foot problems and deformations play an important role. They may help monitor changes in the feet over time or evaluate the effect of therapy in research and in clinical settings, but, therefore, high accuracy and high reliability are indispensable.

However, no accuracy or reliability data can be found for the different devices, except for the 3Space FASTRAK (Polhemus, Colchester, Vermont), an electromagnetic digitizing device. ${ }^{15}$ Kunde et $\mathrm{al}^{18}$ stated that the INFOOT 3-D foot scanning system (I-Ware Laboratory Co Ltd, Osaka, Japan) proved to be suitable, but they did not elaborate. Witana et $\mathrm{al}^{13}$ compared manual measurements with those obtained with the Yeti scanner software (Vorum Research Corp, Vancouver, British Columbia, Canada) and those calculated with their own developed algorithms. They revealed significant differences among the three data sets for most foot dimensions, although the variations in differences were relatively small. ${ }^{13}$

This study was designed to investigate the validity and reliability of the INFOOT 3-D digitizer (INFOOT USB, standard type; I-Ware Laboratory Co Ltd) when used in a population with rheumatoid arthritis.

\section{Methods}

\section{Participants}

Seven patients (five women and two men) volunteered to participate. Their ages varied between 58 and 72 years. They had a mean \pm SD body weight of $77.4 \pm 16.7 \mathrm{~kg}$ and body height of $167.7 \pm 9.2 \mathrm{~cm}$. They all had a confirmed diagnosis of rheumatoid arthritis based on the American College of Rheumatology criteria ${ }^{20}$ and clinically determined foot deformities. Their disease duration varied between 11 and 30 years. Ethical committee approval was obtained by the Ghent University Hospital Ethical Review Board, and all of the participants signed an informed consent form.

\section{Data Acquisition}

All of the measurements were performed in the late morning to avoid the influence of changes in foot volume that might occur in this population. Green velvet markers with a diameter of $5 \mathrm{~mm}$ and a thickness of $2 \mathrm{~mm}$ (I-Ware Laboratory Co Ltd) were used. Markers were placed bilaterally with the participants standing so that the feet were in a loaded condition to minimize skin movement between marker placement and measurement. The markers were placed on the landmarks following the instructions of the manufacturer (Fig. 1).

The participants were then asked to step with the right foot into the INFOOT digitizer while the left foot was placed next to the scanner on a step with the exact same height as the glass plate in the scanner. They were asked to stand still and relaxed and to distribute their bodyweight equally over both feet (Fig. 2).

Scanning was performed at a scan pitch of 1.0 

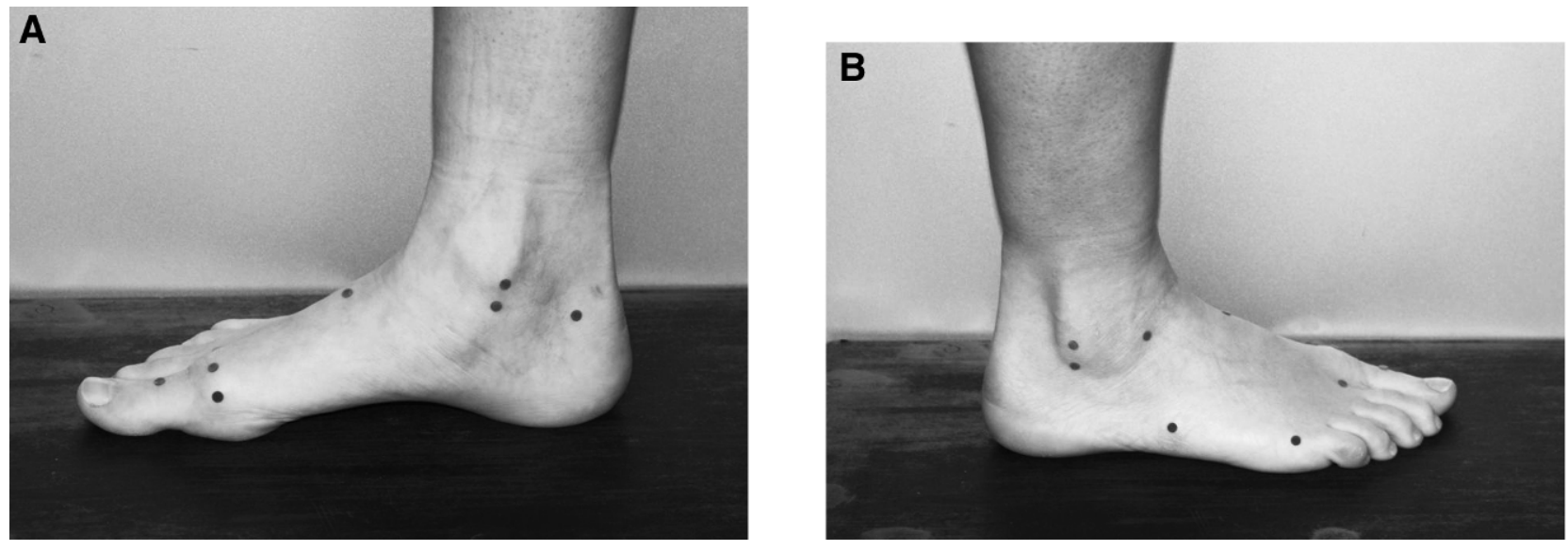

Figure 1. Marker placement $(A)$ medial view, $(B)$ lateral view.

mm using an optical laser scanning procedure. The participants were not allowed to move their feet while scanning $(\sim 5 \mathrm{sec})$. The scanning data were then stored, and the right foot was removed from the digitizer. The glass plate in the digitizer was then wiped with glass cleaner to remove dust and prints. The same procedure was followed for the left foot. This routine was repeated three times for each individual. The data were processed with the accompanying software (I-Ware Laboratory Co Ltd), which provides the following dimensions: foot length, ball girth circumference, foot breadth, instep circumference, heel breadth, instep length, fibular instep length, top of ball girth height, instep height, toe 1 angle, toe 5 angle, toe 1 joint height, toe 5 joint height, navicular height, sphyrion fibulare height, sphyrion height, most lateral point of the lateral malleolus height, most medial point of the medial malleolus height, heel girth circumference, heel bone angle, and foot size. The automated marker recognition and placement were checked and manually adjusted when needed (Fig. 3).

Four clinical measurements were obtained. Foot length (between the most posterior part of the heel and the most anterior part of the longest toe) and forefoot width (between the lateral side of the fifth metatarsal head and the medial side of the first metatarsal head) were measured with a sliding caliper (Seca GmbH \& Co KG, Hamburg, Germany). Navicular and medial malleolus heights were measured with a ruler (Seca $\mathrm{GmbH} \&$ Co kg) (Fig. 4).

\section{Statistical Analysis}

Reliability refers to the consistency of a measurement tool ${ }^{21,22}$ or the absence of measurement error. $^{23}$ To determine the difference between participants, reliability is best described as a ratio of variance based on the between-participants variability compared with the variance within participants. ${ }^{21,}{ }^{22}$ Intraclass correlation coefficients (ICCs) can be used to express this ratio, which reflects the relative reliability of the measure. ${ }^{21}$ The closer the ratio is to 1 , the higher the reliability. ${ }^{22,24}$ According to Portney and Watkins, ${ }^{24}$ values of 0.75 and greater are indicative of good reliability and those less than 0.75 of poor to moderate reliability. A way to indicate absolute reliability is the SEM. ${ }^{21-23}$ The SEM is expressed in the actual unit of the measurement, which is very useful: the smaller the SEM, the more reliable the results. ${ }^{23}$ Using the sample $\mathrm{SD}$ in the equation $\mathrm{SEM}=\mathrm{SD} \sqrt{1-I C C}$ partially cancels out the interindividual variation used in calculation of the ICC. ${ }^{23}$ The smallest detectable difference is the smallest effect that

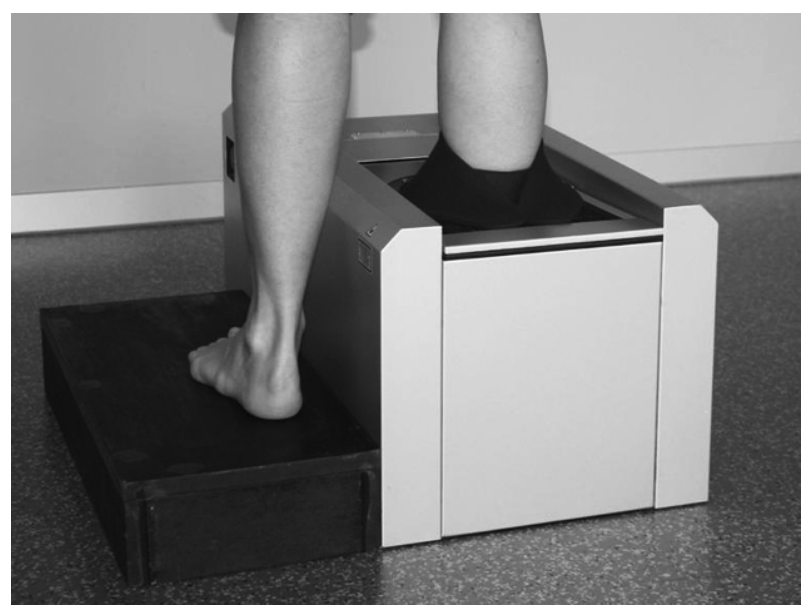

Figure 2. A participant positioned in the INFOOT digitizer. 

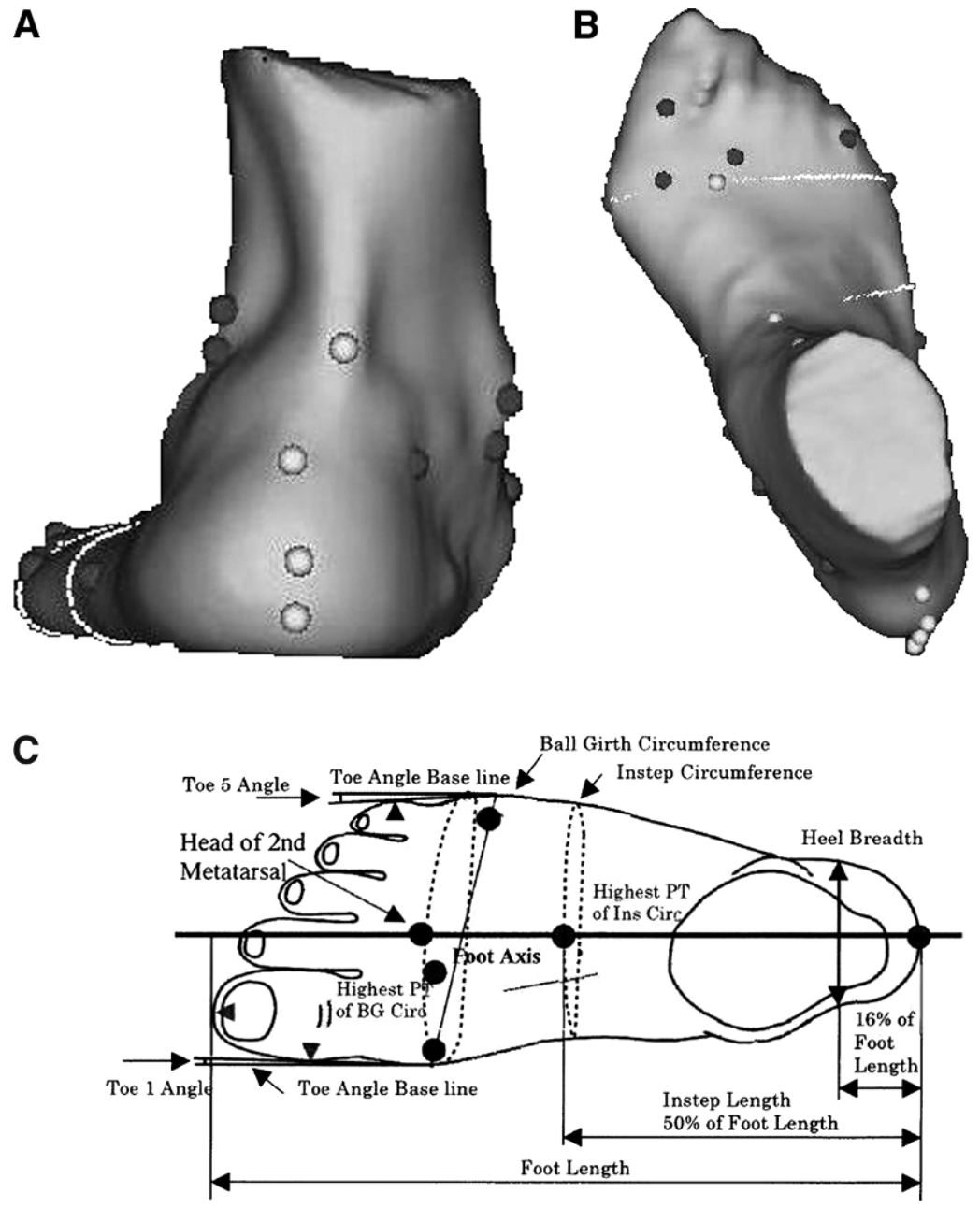

D

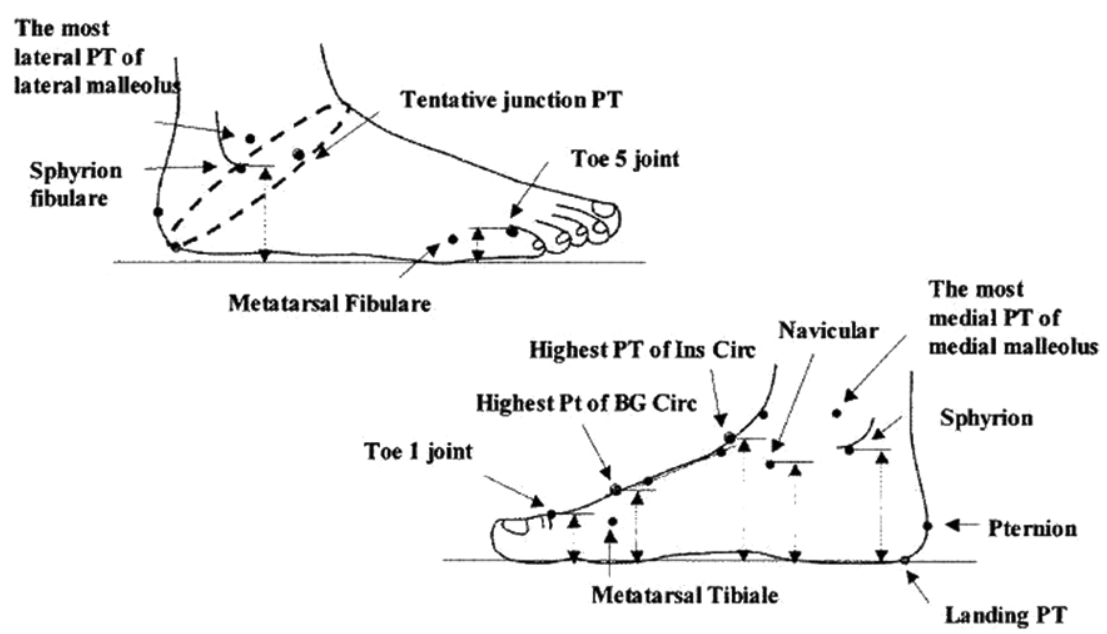

Figure 3. Image and measures provided by the INFOOT digitizer. (A) Three-dimensional image, posterior view; (B) three-dimenstional image, superior view; (C) superior view of measures taken by the digitizer; (D) lateral and medial view of measures taken by the digitizer, $\mathrm{PT}=$ point, Ins Circ $=$ Instep Circumference, BG Circ = Ball Girth Circumference. 

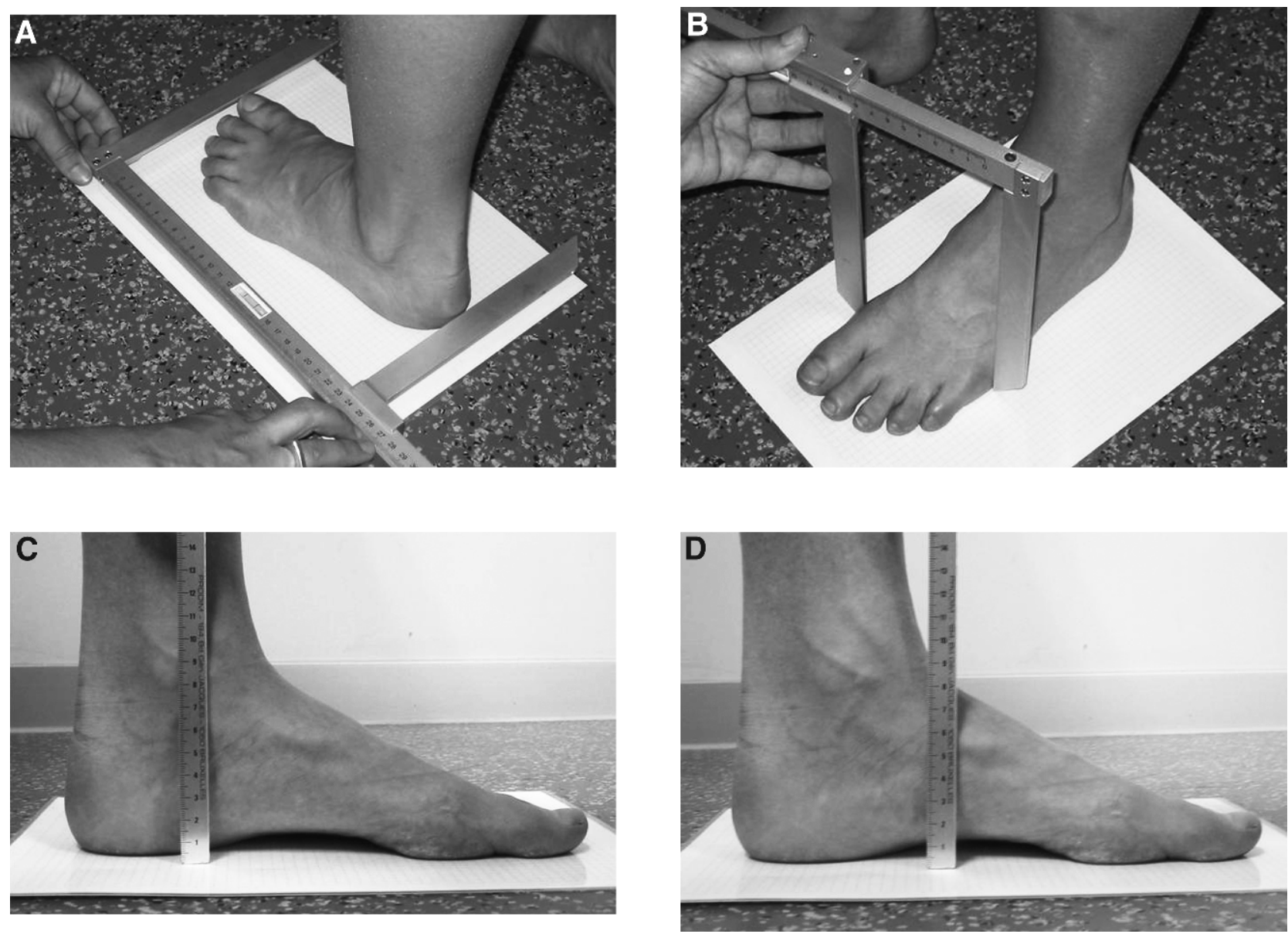

Figure 4. The anthropometric measurements: foot length $(A)$, forefoot width $(B)$, medial malleolus height (C), and navicular height (D).

can be detected as significant. ${ }^{25}$ It is the amount of difference for which anything smaller cannot be reliably distinguished from random error in the measurement. ${ }^{26}$ The size of the smallest detectable difference depends on the responsiveness of the measurement instrument and the sensitivity of the statistical method. ${ }^{25}$ To compare the different variables, the smallest detectable difference percentage can be used.

Validity is often defined as whether a test measures what it is supposed to measure. ${ }^{27}$ It is the measure of the ability of an outcome score to represent the phenomenon under study. Validity can be demonstrated by means of comparison with the gold-standard measurement. ${ }^{28}$

The data were exported to SPSS 16.0 (SPSS Inc, Chicago, Illinois) for statistical analyses. Nonparametric Friedman tests were performed to evaluate whether significant differences among the three trials could be demonstrated for any of the parameters investigated. As a measure of relative reliability, two-way mixed ICCs for absolute agreement were calculated. According to Shrout and Fleiss ${ }^{29}$ these ICCs correspond to the classification ICC [3,3]. In addition to ICCs, SEMs, smallest detectable differences, and smallest detectable difference percentage values were calculated as measures of absolute reliability. ${ }^{22,} 23$

To assess the validity of the INFOOT 3-D foot digitizer, Pearson correlation coefficients were calculated between the digitizer's data and the clinical measurements. A Pearson correlation coefficient can be considered to be a validity coefficient because it is being used to measure the relationship between a score and an independent criterion test. ${ }^{28}$ For all of the tests, the level of significance was set at $\alpha=0.05$.

\section{Results}

Descriptive values for all of the foot digitizer parameters obtained are summarized in Table 1 . 
Table 1. Mean (SD) Values of the INFOOT Three-dimensional Foot Measures

\begin{tabular}{|c|c|c|c|}
\hline Parameter & Trial 1 & Trial 2 & Trial 3 \\
\hline R Foot length (mm) & $250.9(24.71)$ & $251.5(24.94)$ & $252.5(25.16)$ \\
\hline L Foot length (mm) & $249.7(27.02)$ & $250.1(26.87)$ & $250.1(26.83)$ \\
\hline R Ball girth circumference (mm) & $244.4(17.3)$ & $243.9(17.68)$ & $246.1(17.4)$ \\
\hline L Ball girth circumference (mm) & $246.3(23.5)$ & $241.9(19.94)$ & $242.8(21.51)$ \\
\hline R Foot breadth (mm) & $102.9(7.36)$ & $102.7(7.33)$ & $103.9(7.52)$ \\
\hline L Foot breadth (mm) & $102.9(9.37)$ & $102.7(9.00)$ & $103.4(9.86)$ \\
\hline R Instep circumference (mm) & $244.8(15.20)$ & $243.9(13.72)$ & $244.4(14.95)$ \\
\hline L Instep circumference (mm) & $241.9(10.91)$ & $242.8(10.56)$ & $242.8(10.33)$ \\
\hline R Heel breadth $(\mathrm{mm})$ & $68.0(4.77)$ & $68.2(4.95)$ & $68.3(5.03)$ \\
\hline L Heel breadth (mm) & $67.8(4.97)$ & $67.9(4.66)$ & $68.1(4.62)$ \\
\hline R Instep length (mm) & $189.1(12.66)$ & $189.5(13.00)$ & $190.9(12.80)$ \\
\hline L Instep length (mm) & $190.7(12.79)$ & $191.6(12.19)$ & $192.8(14.45)$ \\
\hline R Fibular instep length (mm) & $160.7(11.28)$ & $161.7(10.46)$ & $160.1(12.15)$ \\
\hline L Fibular instep length (mm) & $159.3(13.96)$ & $160.3(12.60)$ & $158.8(12.89)$ \\
\hline $\mathrm{R}$ Top of ball girth height (mm) & $39.4(2.60)$ & $39.2(2.87)$ & $38.6(2.65)$ \\
\hline L Top of ball girth height (mm) & $39.3(5.30)$ & $38.3(4.72)$ & $38.2(4.38)$ \\
\hline R Instep height (mm) & $65.1(7.33)$ & $64.3(7.44)$ & $63.8(7.93)$ \\
\hline L Instep height (mm) & $64.3(9.14)$ & $63.6(7.59)$ & $63.1(7.09)$ \\
\hline $\mathrm{R}$ Toe 1 angle $\left({ }^{\circ}\right)$ & $18.7(13.29)$ & $18.9(14.35)$ & $19.2(13.89)$ \\
\hline L Toe 1 angle $\left({ }^{\circ}\right)$ & $29.9(18.60)$ & $29.8(18.26)$ & $31.0(17.20)$ \\
\hline $\mathrm{R}$ Toe 5 angle $\left({ }^{\circ}\right)$ & $14.8(5.90)$ & $14.3(6.00)$ & $13.8(6.08)$ \\
\hline L Toe 5 Angle $\left({ }^{\circ}\right)$ & $11.2(7.68)$ & $11.5(6.40)$ & $11.4(6.51)$ \\
\hline $\mathrm{R}$ Toe 1 joint height $(\mathrm{mm})$ & $27.2(2.76)$ & $27.0(1.80)$ & $26.3(3.16)$ \\
\hline L Toe 1 joint height (mm) & $27.9(4.67)$ & $26.7(3.05)$ & $26.8(3.32)$ \\
\hline $\mathrm{R}$ Toe 5 joint height $(\mathrm{mm})$ & $23.4(3.90)$ & $23.1(4.98)$ & $21.9(5.19)$ \\
\hline L Toe 5 joint height (mm) & $24.5(6.83)$ & $23.6(6.74)$ & $23.2(6.71)$ \\
\hline R Navicular height (mm) & $40.2(8.29)$ & $40.3(8.35)$ & $39.6(7.63)$ \\
\hline L Navicular height (mm) & $41.1(10.91)$ & $40.0(10.35)$ & $40.2(11.36)$ \\
\hline R Sphyrion fibulare height (mm) & $51.6(5.83)$ & $50.4(5.62)$ & $50.5(5.51)$ \\
\hline L Sphyrion fibulare height (mm) & $59.0(7.50)$ & $57.3(9.17)$ & $59.0(7.47)$ \\
\hline R Sphyrion height (mm) & $58.4(9.51)$ & $60.2(8.92)$ & $50.8(24.89)$ \\
\hline L Sphyrion height $(\mathrm{mm})$ & $57.7(13.87)$ & $57.3(11.40)$ & $59.5(10.62)$ \\
\hline R Lateral point of lateral malleolar height $(\mathrm{mm})$ & $66.5(6.38)$ & $67.1(10.11)$ & $55.8(25.18)$ \\
\hline L Lateral point of lateral malleolar height $(\mathrm{mm})$ & $73.0(7.69)$ & $70.3(9.56)$ & $72.4(8.01)$ \\
\hline R Medial point of medial malleolar height $(\mathrm{mm})$ & $71.6(10.64)$ & $72.5(8.49)$ & $72.9(7.06)$ \\
\hline L Medial point of medial malleolar height $(\mathrm{mm})$ & $73.2(11.46)$ & $72.2(10.48)$ & $73.8(10.47)$ \\
\hline $\mathrm{R}$ Heel bone angle $\left({ }^{\circ}\right)$ & $5.5(4.87)$ & $5.4(4.16)$ & $6.0(4.97)$ \\
\hline L Heel bone angle $\left({ }^{\circ}\right)$ & $2.4(5.72)$ & $4.2(3.47)$ & $5.6(4.84)$ \\
\hline
\end{tabular}

Abbreviations: $L$, left; $R$, right.

No significant differences were demonstrated for any of the parameters among the three trials $(P>$ .05 for all) except for right foot length $(P=.001)$, right navicular height $(P=.05)$, and right sphyrion height $(P=.034)$.

Most of the 38 parameters showed ICCs of 0.75 or greater, indicating good reliability among the three trials. ${ }^{24}$ Thirty parameters demonstrated ICCs greater than 0.9 and seven parameters displayed ICCs greater than 0.8 . One parameter, the left heel bone angle, expressed a moderate correlation, with an ICC of $0.609 .{ }^{24}$ All of the ICCs demonstrated $P<$ .001 except left heel bone angle $(P>.05)$ (Table 2$)$.

The SEM values varied between 0.31 and $3.51 \mathrm{~mm}$ 
Table 2. Reliability of the INFOOT Three-dimensional Foot Measures

\begin{tabular}{|c|c|c|c|c|c|}
\hline Parameter & $P$ Value of Friedman Test & ICC & SEM & SDD & SDD \% \\
\hline R Foot length (mm) & .001 & $0.999^{a}$ & 0.79 & 2.19 & 0.87 \\
\hline L Foot length $(\mathrm{mm})$ & .446 & $0.999^{a}$ & 0.85 & 2.36 & 0.94 \\
\hline R Ball girth circumference (mm) & .565 & $0.975^{a}$ & 2.76 & 7.65 & 3.13 \\
\hline L Ball girth circumference (mm) & .276 & $0.926^{a}$ & 5.90 & 16.36 & 6.72 \\
\hline R Foot breadth (mm) & .097 & $0.975^{a}$ & 1.17 & 3.24 & 3.15 \\
\hline L Foot breadth (mm) & .317 & $0.981^{a}$ & 1.30 & 3.60 & 3.49 \\
\hline R Instep circumference (mm) & .565 & $0.991^{a}$ & 1.39 & 3.85 & 1.57 \\
\hline L Instep circumference (mm) & .018 & $0.995^{a}$ & 0.75 & 2.08 & 0.86 \\
\hline R Heel breadth (mm) & .317 & $0.996^{a}$ & 0.31 & 0.86 & 1.26 \\
\hline L Heel breadth (mm) & .459 & $0.986^{a}$ & 0.56 & 1.56 & 2.30 \\
\hline R Instep length (mm) & .102 & $0.983^{a}$ & 1.67 & 4.63 & 2.44 \\
\hline L Instep length (mm) & .565 & $0.947^{a}$ & 3.03 & 8.41 & 4.39 \\
\hline R Fibular instep length (mm) & .867 & $0.968^{a}$ & 2.02 & 5.61 & 3.49 \\
\hline L Fibular instep length (mm) & .341 & $0.929^{a}$ & 3.51 & 9.72 & 6.10 \\
\hline $\mathrm{R}$ Top of ball girth height (mm) & .054 & $0.926^{a}$ & 0.74 & 2.04 & 5.22 \\
\hline L Top of ball girth height (mm) & .254 & $0.935^{a}$ & 1.23 & 3.40 & 8.82 \\
\hline R Instep height (mm) & .156 & $0.977^{a}$ & 1.15 & 3.18 & 4.94 \\
\hline L Instep height (mm) & .630 & $0.964^{a}$ & 1.52 & 4.20 & 6.60 \\
\hline $\mathrm{R}$ Toe 1 angle $\left({ }^{\circ}\right)$ & .459 & $0.996^{a}$ & 0.88 & 2.43 & 12.84 \\
\hline L Toe 1 angle $\left({ }^{\circ}\right)$ & .867 & $0.983^{a}$ & 2.35 & 6.52 & 21.55 \\
\hline $\mathrm{R}$ Toe 5 angle $\left({ }^{\circ}\right)$ & .066 & $0.983^{a}$ & 0.78 & 2.17 & 15.18 \\
\hline L Toe 5 angle $\left({ }^{\circ}\right)$ & .163 & $0.957^{a}$ & 1.43 & 3.96 & 34.79 \\
\hline $\mathrm{R}$ Toe 1 joint height (mm) & .396 & $0.899^{a}$ & 0.84 & 2.32 & 8.65 \\
\hline L Toe 1 joint height $(\mathrm{mm})$ & .651 & $0.883^{a}$ & 1.28 & 3.55 & 13.09 \\
\hline $\mathrm{R}$ Toe 5 joint height (mm) & .680 & $0.927^{a}$ & 1.28 & 3.54 & 15.53 \\
\hline L Toe 5 joint height $(\mathrm{mm})$ & .368 & $0.955^{a}$ & 1.43 & 3.97 & 16.73 \\
\hline R Navicular height (mm) & .050 & $0.984^{a}$ & 1.02 & 2.84 & 7.09 \\
\hline L Navicular height (mm) & .565 & $0.964^{a}$ & 2.06 & 5.72 & 14.16 \\
\hline R Sphyrion fiburale height (mm) & .698 & $0.939^{a}$ & 1.40 & 3.87 & 7.62 \\
\hline L Sphyrion fiburale height (mm) & .867 & $0.876^{a}$ & 2.85 & 7.89 & 13.50 \\
\hline R Sphyrion height (mm) & .034 & $0.933^{a}$ & 4.20 & 11.64 & 20.61 \\
\hline L Sphyrion height (mm) & .772 & $0.881^{a}$ & 4.15 & 11.52 & 19.80 \\
\hline $\mathrm{R}$ Lateral point of lateral malleolus height $(\mathrm{mm})$ & .867 & $0.880^{a}$ & 5.58 & 15.45 & 24.48 \\
\hline L Lateral point of lateral malleolus height (mm) & .565 & $0.861^{a}$ & 3.16 & 8.75 & 12.16 \\
\hline $\mathrm{R}$ Medial point of medial malleolus height $(\mathrm{mm})$ & .618 & $0.618^{a}$ & 1.06 & 2.08 & 5.76 \\
\hline L Medial point of medial malleolus height $(\mathrm{mm})$ & .250 & $0.954^{a}$ & 0.77 & 2.32 & 6.43 \\
\hline R Heel bone angle $\left({ }^{\circ}\right)$ & .867 & $0.802^{a}$ & 2.08 & 5.77 & 102.52 \\
\hline L Heel bone angle $\left({ }^{\circ}\right)$ & .254 & $0.609^{b}$ & 2.98 & 8.26 & 202.68 \\
\hline
\end{tabular}

Abbreviations: ICC, intraclass correlation coefficient; L, left; R, right; SDD, smallest detectable difference.

ap $<.001$.

${ }^{b} P<.05$.

for the length and width measures, between 0.74 and $5.58 \mathrm{~mm}$ for the height data, between 0.75 and $5.9 \mathrm{~mm}$ for the circumferences, and between $0.78^{\circ}$ and $2.98^{\circ}$ for the angles (Table 2). The smallest detectable difference values for length, width, height, and circumference measures ranged from
0.86 to $16.36 \mathrm{~mm}$; and for angle measures, from $2.17^{\circ}$ to $8.26^{\circ}$.

Comparing the smallest detectable difference percentage values among all of the parameters, the length, width, and circumference measurements showed lower smallest detectable difference per- 
Table 3. Pearson Correlation Coefficients Between the Foot Digitizer Data and the Clinical Data

\begin{tabular}{lcc}
\hline Parameter & $\begin{array}{c}\text { Pearson } \\
\text { Correlation } \\
\text { Coefficient }\end{array}$ & $P$ Value \\
\hline L Foot length $(\mathrm{mm})$ & 0.997 & $<.001$ \\
R Foot length $(\mathrm{mm})$ & 0.994 & $<.001$ \\
L Foot breadth $(\mathrm{mm})$ & 0.924 & $<.05$ \\
R Foot breadth $(\mathrm{mm})$ & 0.978 & $<.001$ \\
L Medial point of medial malleolus & 0.808 & $<.05$ \\
$\quad$ height (mm) & & \\
R Medial point of medial malleolus & 0.801 & $<.05$ \\
$\quad$ height (mm) & & \\
L Navicular height (mm) & 0.922 & $<.05$ \\
R Navicular height $(\mathrm{mm})$ & 0.750 & $<.05$ \\
\hline
\end{tabular}

Abbreviations: $L$, left; $R$, right.

centages than did the height-related measurements. The angle data demonstrated the highest smallest detectable difference percentage values (Table 2).

Concerning the validity of the INFOOT 3-D foot digitizer data compared with clinical measurements, high Pearson correlation coefficients, ranging from 0.750 to 0.997 , can be seen between the foot digitizer data and the clinical data, indicating good validity (Table 3).

\section{Discussion}

Most variables demonstrated good to very good validity and reliability. This is shown by the combination of high Pearson correlation coefficients, no significant differences in the Friedman test, high ICCs, low SEM values, and low smallest detectable difference and smallest detectable difference percentage values.

\section{Reliability}

Linear measurements seemed to give more reliable results than do angular measurements. Length, breadth, and circumference measurements showed excellent reliability, with ICC values greater than $0.9^{29}$ and smallest detectable difference percentage values less than $6.72 \%$. The SEM values for the breadth measurements varied between 0.3 and 1.3 $\mathrm{mm}$, for the length measurements between 0.7 and $3.5 \mathrm{~mm}$, and for the circumference measurements between 0.7 and $5.9 \mathrm{~mm}$. The height parameters also present high correlation coefficients, all greater than 0.8 , indicating very good reliability. ${ }^{29}$ The smallest detectable difference percentages $(4.94 \%$ $24.48 \%$ ) are a little higher than for the previously mentioned parameters but also still indicating high reliability. When looking at the SEM, the highest value found is $5.58 \mathrm{~mm}$ for the right lateral malleolus height. The angle data proved to be less reliable. The toe angles still showed a very high ICC $(>0.9)$, but the smallest detectable difference percentages illustrate a higher dispersion, with values ranging from $12 \%$ to $34 \%$. Despite those, the SEM values ranged from $0.88^{\circ}$ and $2.35^{\circ}$, and the smallest detectable differences showed values of $2.17^{\circ}$ to $6.52^{\circ}$ for the toe angles, which are clinically still acceptable.

The angle of the heel bone seems to be the least reliable measure, with a good ICC right (ICC = $0.802)$ but only a fair ICC left $(\mathrm{ICC}=0.609),{ }^{29}$ and high smallest detectable difference percentages (right, 102.52\% and left, 202.68\%). The heel bone angle is calculated by three landmarks, and it is related to the midpoint of two defined cross sections relative to foot length, which might increase the risk of errors.

\section{Validity}

Although a large interest in the treatment of the lower extremity has yielded a host of proposed measurements to quantify the foot, little attention has been given to robust inquiry into the reliability and validity of these techniques. ${ }^{30}$ Because there is no real gold standard for clinical anthropometric measurements of the foot, foot length, foot breadth, and navicular and medial malleolar height were chosen for the validity study because they represent measurements in different dimensions. Pearson correlation coefficients between the foot digitizer data and the clinical data varied between 0.750 and 0.997 ( $P<.05$ for all), proving good validity.

Toe deformities are some of the main features of the foot deformation in rheumatoid arthritis. Hence, refining the data in the toe area and providing more detailed information about all the toes, not only toes 1 and 5, would be beneficial. Another striking feature of the rheumatoid arthritis foot is the pes planovalgus deformation. Therefore, the heel bone angle would be a useful measure. However, it is the least reliable one at the moment. Reducing the possible amount of error in this parameter is needed. Foot measurements are often normalized using the truncated foot length, hence, providing these data would make comparisons easier.

Based on the good reliability and validity of most of the parameters and considering that the others still provide clinically acceptable values, the INFOOT 3-D foot digitizer may be a valuable tool to 
use for monitoring feet in patients with rheumatoid arthritis. It is far less time consuming than clinical measurements, where several measurements are needed to obtain a full picture of the foot. With the digitizer, only one scan provides measurements in all of the dimensions of the complete foot. Compared with radiographic techniques, it is less harmful because patients are not exposed to ionizing radiation.

This study was performed with patients with rheumatoid arthritis and deformed feet. Caution should be taken when extrapolating the results to different patient populations, specifically those with pronounced foot deformities. Further investigations are needed in different patient populations. It might also be valuable to compare the surface marker setting with the underlying skeleton to know how closely the palpated points are related to the bony structure, specifically in severely swollen feet. In this study, all of the patients were tested in the late morning. Testing them at different times of the day might provide useful information on the foot volumetric variability in this population.

\section{Conclusions}

Given the good reliability and validity of most of the parameters, the INFOOT digitizer proved to be a useful tool for measuring the foot in 3-D in a population with rheumatoid arthritis. Only the angle data should be interpreted with caution, although they still provide clinically acceptable values. In the same population, high validity is shown for measurements in different dimensions compared with clinical measurements.

\section{Financial Disclosure: None reported. Conflict of Interest: None reported.}

\section{References}

1. Helmick CG, Felson DT, Lawrence RC, et al: Estimates of the prevalence of arthritis and other rheumatic conditions in the United States. Arthritis Rheum 58: 15, 2008.

2. Grondal L, Tengstrand B, Nordmark B, et al: The foot: still the most important reason for walking incapacity in rheumatoid arthritis: distribution of symptomatic joints in 1,000 RA patients. Acta Orthopaed 79: 257, 2008.

3. Michelson J, Easley M, Wigley FM, et al: Foot and ankle problems in rheumatoid-arthritis. Foot Ankle Int 15: 608, 1994.

4. Billis E, Katsatkiori E, Kapodistrias C, et al: Assessment of foot posture: correlation between different clinical techiniques. The Foot 17: 65, 2007.

5. Platto MJ, Oconnell PG, Hicks JE, et AL: The relationship of pain and deformity of the rheumatoid foot to gait and an index of functional ambulation. J Rheumatol 18: 38, 1991.

6. Redmond AC, Crosbie J, Ouvrier RA: Development and validation of a novel rating system for scoring standing foot posture: the Foot Posture Index. Clin Biomech 21: 89, 2006.

7. Budiman-Mak E, Roach KE, Stuck R, et aL: Radiographic measurement of hallux valgus in the rheumatoid arthritic foot. J Rheumatol 21: 623, 1994.

8. Mall NA, Hardaker WM, Nunley JA, ET AL: The reliability and reproducibility of foot type measurements using a mirrored foot photo box and digital photography compared to caliper measurements. J Biomech 40: 1171, 2007.

9. Chen MJ, Chen CP, Lew HL, et aL: Measurement of forefoot varus angle by laser technology in people with flexible flatfoot. Am J Phys Med Rehabil 82: 842, 2003.

10. LIU X, Kim W, Drerup B: "3D Characterization and Localization of Anatomical Landmarks of the Foot," in Proceedings of the 2004 ACM SIGGRAPH International Conference on Virtual Reality Continuum and Its Applications in Industry, p 253, Association for Computing Machinery, New York, 2004.

11. Mochimaru M, Kouchi M, Dohi M: Analysis of 3-D human foot forms using the Free Form Deformation method and its application in grading shoe lasts. Ergonomics 43: 1301, 2000.

12. Tsung BY, Zhang M, FAn YB, et AL: Quantitative comparison of plantar foot shapes under different weight-bearing conditions. J Rehabil Res Dev 40: 517, 2003.

13. Witana CP, Xiong SP, Zhao JH, ET AL: Foot measurements from three-dimensional scans: a comparison and evaluation of different methods. Int J Industrial Ergonom 36: 789, 2006.

14. Houston VL, Luo G, Mason CP, Et AL: Changes in male foot shape and size with weightbearing. JAPMA 96: 330, 2006.

15. Liu W, Miller J, Stefanyshyn D, et AL: Accuracy and reliability of a technique for quantifying foot shape, dimensions and structural characteristics. Ergonomics 42: 346, 1999.

16. Luximon A, Goonetilueke RS, Zhang M: 3D foot shape generation from 2D information. Ergonomics 48: 625, 2005.

17. Krauss I, Grau S, Mauch M, Et al: "Female Foot Morphology: Implications for Last Design," Proceedings of the 8th Footwear Biomechanics Symposium, Taipei 2007, ed by EC Frederick, SW Yang p 39, Footwear Biomechanics Corp, Brentwood, OH, 2007.

18. Kunde S, Sterzing T, Milani T: "The Influence of Body Position and Physical Activity on Foot Dimensions Measured by a Foot Scanning System," Proceedings 8th Footwear Biomechanics Symposium, Taipei 2007, ed by EC Frederick, SW Yang p 43, Footwear Biomechanics Corp, Brentwood, OH, 2007.

19. Witana CP, Feng J, Goonetilleke RS: Dimensional differences for evaluating the quality of footwear fit. Ergonomics 47: 1301, 2004.

20. ARnett FC, Edworthy SM, Bloch DA, ET AL: The American Rheumatism Association 1987 revised criteria for the 
classification of rheumatoid arthritis. Arthritis Rheum 31: 315, 1988.

21. Coorevits P, Danneels L, CAmbier D, et al: Test-retest reliability of wavelet- and Fourier based EMG (instantaneous) median frequencies in the evaluation of back and hip muscle fatigue during isometric back extensions. J Electromyogr Kinesiol 18: 798, 2008.

22. WEIR JP: Quantifying test-retest reliability using the intraclass correlation coefficient and the SEM. J Strength Cond Res 19: 231, 2005.

23. AtKInSON G, Nevill AM: Statistical methods for assessing measurement error (reliability) in variables relevant to sports medicine. Sports Med 26: 217, 1998.

24. Portney L, Watkins M: "Statistical Measures of Reliability," in Foundations of Clinical Research: Applications to Practice, ed by M Cohen p 585, Pearson Education International, Upper Saddle River, NJ, 2009.

25. Angst F, Aeschlimann A, Stucki G: Smallest detectable and minimal clinically important differences of rehabilitation intervention with their implications for required sample sizes using WOMAC and SF-36 quality of life measurement instruments in patients with osteoarthritis of the lower extremities. Arthritis Rheum 45: 384, 2001.

26. Lassere MN, van Der Heijde D, Johnson KR, ET AL: Reliability of measures of disease activity and disease damage in rheumatoid arthritis: implications for smallest detectable difference, minimal clinically important difference, and analysis of treatment effects in randomized controlled trials. J Rheumatol 28: 892, 2001.

27. Anastasi A: Psychological Testing, 6th Ed, Macmillan Publishing Co, New York, 1988.

28. IBrahim T, Beiri A, AzZabi M, et AL: Reliability and validity of the subjective component of the American Orthopaedic Foot and Ankle Society clinical rating scales. J Foot Ankle Surg 46: 65, 2007.

29. Shrout PE, Fleiss JL: Intraclass correlations: uses in assessing rater reliability. Psychol Bull 86: 420, 1979.

30. Wrobel JS, Armstrong DG: Reliability and validity of current physical examination techniques of the foot and ankle. JAPMA 98: 197, 2008. 